\title{
Nursing students' perceptions and experiences of concept mapping as a learning tool in a human physiology course
}

\author{
V Nuuyoma, MPhil HPE, PhD Nursing Education; S K Fillipus, BNSc \\ School of Nursing, Faculty of Health Sciences, University of Namibia, Rundu, Namibia
}

Corresponding author: V Nuuyoma (vistolina.nuuyoma@gmail.com)

Background. Nursing students perceive human physiology as one of the most challenging courses, and it is also the course most often failed. To address this perceived challenge, a university campus introduced concept mapping to facilitate learning among nursing students in the human physiology course. Despite evidence of its use in other disciplines and educational contexts, it is not known how nursing students perceive and experience its use when learning human physiology.

Objective. To explore and describe the perceptions and experiences of nursing students' use of concept mapping as a learning tool in a human physiology course.

Methods. A qualitative descriptive study was conducted at a university campus in Namibia. Data were obtained through three focus group discussions with 18 second-year nursing students in the Bachelor of Nursing Science (Clinical) Honours programme, who were conveniently sampled. Transcriptions from the discussions were analysed following Tesch's 8-step coding process. Ethical approval and permission to conduct the study were granted by the campus Research Ethics Committee in the School of Nursing, University of Namibia.

Results. Four themes emerged from the analysis: concept mapping facilitates deep learning; concept mapping as a group activity; effects of concept mapping on students' academic performance; and implications of concept mapping for learning resources.

Conclusion. Nursing students had positive experiences and perceptions of concept mapping as a learning tool for human physiology. However, students felt that this learning tool is time consuming and requires many learning resources. Considering its benefits for learning, it is recommended that concept mapping be used as it promotes deep learning, which in turn leads to in-depth knowledge of human physiology. Nevertheless, students should be guided on time-management strategies and learning resource options available in resource-constrained settings.

Afr J Health Professions Educ 2020;12(3):98-102. https://doi.org/10.7196/AJHPE.2020.v12i3.1330

Concept mapping refers to a strategy where concepts are organised conceptually in the form of graphical networks, ${ }^{[1]}$ providing a pictorial view of the knowledge presented. In concept mapping, concepts are displayed in boxes or circles that are joined by phrases or words that describe the association between the ideas. ${ }^{[2]}$ The strategy aims to develop students' cognitive structures by establishing linkages and relationships between bodies of knowledge and linking theory to practice. ${ }^{[3,4]}$ By means of concept mapping, students develop critical thinking and judgement skills. ${ }^{\left[{ }^{[5}\right.}$ Concept maps are underpinned by the assimilation theory of meaningful learning created by the psychologist David Ausubel in $1963 .{ }^{[6]}$ In addition to Ausubel's theory, concept mapping is also based on the constructivist teaching and learning approach.

Since its introduction, concept mapping has been effectively practised in disciplines such as mathematics, chemistry, education and policy studies. ${ }^{[2]}$ According to Vodovozov and Raud, ${ }^{[7]}$ concept mapping may be used as a teaching, learning and assessment tool. Moreover, it is suitable for use as a research tool, ${ }^{[8]}$ as a curriculum-development tool, as well as a reflection tool. ${ }^{[5]}$ In nursing education, concept mapping is a useful tool, assisting students to plan patient care, and clinical educators may use it to teach clinical nursing. ${ }^{[9]}$ When used as a learning tool, concept mapping improves learning outcomes and helps to clarify learning objectives. ${ }^{[7]}$ In a study conducted in Egypt, $68.3 \%$ of nursing students agreed that concept mapping helped them to understand concepts, while $71.7 \%$ agreed that their performance improved with the use of concept maps. ${ }^{[10]}$ In the literature, other benefits of concept mapping are an improvement of students' cognitive abilities and the ability to develop clinically competent nurses. ${ }^{[11]}$ Furthermore, concept mapping is also suitable for use as a tool for self-evaluation. Despite the benefits and positive effects of using concept mapping as a learning tool, it is rarely used by nursing students at one of the public universities in Namibia.

Human physiology is perceived as one of the challenging courses in the undergraduate nursing degree programme offered at one of the public universities in Namibia. This could be due to the large volume of content that is integrative and encompasses difficult concepts. It is one of the courses that is most often failed at second-year level of training, as evidenced by the high number of students who write supplementary examinations, as well as those who register for tutorial classes in the summer and winter terms. Human physiology is offered as a semester course, with written examinations at the end of each semester. The teaching of human physiology is done using interactive lectures, group discussions, online discussion platforms and assignments. Students mostly learn human physiology by memorising the content, discussion with peers, making notes from textbooks and online resources.

The second-year nursing students at a rural campus in north-east Namibia were introduced to concept mapping as a learning tool for human physiology in the 2018 academic year. Concept mapping is used as a 
self-directed learning activity after the lecturer has introduced content in didactic classes. Students submit concept maps in the lecture hall during the human physiology class, usually after completing a particular body system. This is generally submitted as individual work or a group activity. The lecturer evaluates the concept maps and gives feedback using criteria designed according to the content of each body system; therefore, concept maps serve as a tool for formative feedback. The idea of including new learning approaches in nursing is to foster long-term and meaningful learning in students; ${ }^{[11]}$ thus, concept mapping was deemed a suitable option. Given the novelty of concept mapping to nursing students at the public university, the researcher was not aware of how they perceived and experienced its use as a learning tool. Therefore, this article describes the perceptions and experiences of nursing students in the use of concept mapping as a learning tool in a course on human physiology.

\section{Methods}

This qualitative descriptive study was conducted from October to November 2019 at one of the public university campuses in Namibia. The study population consisted of second-year nursing students registered in an undergraduate programme. This population group was included because they used concept mapping as a learning tool in a human physiology course. Participants were conveniently selected to participate in the study and data were obtained from focus group discussions conducted by the principal researcher. The principal researcher was a final-year student in the Bachelor of Nursing Science (Clinical) Honours programme, while the co-researcher, who supervised the research project, is a lecturer in the School of Nursing. Both researchers maintained reflexivity by using reflective notes. Reflexivity means that the researcher reflects on their own biases, values and assumptions and writes about them openly in their research. ${ }^{[12]}$ The principal researcher possesses good communication and group facilitation skills ${ }^{[13]}$ and was therefore able to listen, paraphrase, clarify questions and summarise content during the group discussions. A focus group interview guide was used during the discussion, consisting of the following questions: What is your experience with the use of concept mapping as a learning tool in the human physiology course? How do you perceive concept mapping as a learning tool in the human physiology course?

All second-year students were informed of the study and the researcher confirmed the willingness and availability of the potential participants. They were also informed of their right to withdraw from the study at any point; no coercion or form of threat was used to recruit participants. Furthermore, written informed consent was obtained from all participants prior to participation in the study. Written consent to audio recording was also obtained from each participant prior to the focus group discussions. Data saturation was reached after three discussions, each consisting of 6 participants. The focus group discussions took place on campus and lasted between 49 and 55 minutes. All discussions were audio recorded and then the researchers transcribed the data. Data were analysed manually following Tesch's 8 -step coding process. ${ }^{[14]}$ The coding process started with the researchers reading through all transcriptions to get a sense of the whole and then writing down ideas that came to mind. Thoughts were written down in the margins, followed by making a list of all topics in the margins and clustering similar topics together. The researchers then found the most descriptive wording for the topics and categorised them, forming themes.
The rigour of this study was assured by means of Whittemore et al's $\mathrm{s}^{[15]}$ framework. This framework encompasses four primary criteria that are crucial to all qualitative inquiry, including integrity, authenticity, credibility and criticality. The researchers engaged in self-reflection, self-scrutiny and documentation of all steps during the study to ensure integrity. Authenticity was ensured through verbatim transcription of all data from focus group discussions, and credibility was ensured through peer debriefing, member checking and collection of data until saturation was reached. Peer debriefing was necessary to explore aspects of the study that might otherwise have remained hidden in the researchers' minds, ${ }^{[16]}$ and was done by meeting with the senior researcher, who is experienced in qualitative research. During the meeting, the two researchers presented all steps taken during the study and how themes were developed. Member checking involves checking data, themes and conclusions with participants. This was carried out by one researcher during data collection, as well as after the data were analysed. The purpose was to confirm whether the researchers' interpretations of the findings and conclusions represented what was said by participants. ${ }^{[16]}$ The researchers ensured criticality by engaging in critical thinking throughout all stages of the study. The pre-test of the focus group discussion guide was done with 4 second-year nursing students, who did not participate in the main study; however, the transcriptions of the pre-test were analysed and also form part of the study findings. The project supervisor listened to the audio recording of the pilot study to check the interviewing skills used, and improvements were proposed.

\section{Ethical approval}

Ethical approval and permission to conduct the study were granted by the campus Research Ethics Committee in the School of Nursing at the University of Namibia (ref. no. SF/09/2019).

\section{Results}

Eighteen participants took part in the study. They were aged between 18 and 25 years, including 11 females and 7 males. Four themes emerged from the data analysis: concept mapping facilitates a deep learning approach; concept mapping as a group activity; perceived effects of concept mapping on students' academic performance; and perceived implications of concept mapping on learning resources. Findings are presented in Table 1.

\section{Theme 1: Concept mapping facilitates a deep learning approach}

Students stated that concept mapping made it easier to create linkages between related concepts that are used to explain physiological processes and also to group related concepts together. They further mentioned that concept mapping helped them to engage deeply with the course content because it provokes curiosity to explore physiological processes.

Table 1. Themes for perceptions and experiences of nursing students of the use of concept mapping as a learning tool in human physiology

- Concept mapping facilitates a deep learning approach

- Concept mapping as a group activity

- Perceived effects of concept mapping on students' academic performance

- Perceived implications of concept mapping on learning resources 
Consequently, students tend to read more to understand and are greatly motivated:

'For me, concept mapping is a nice tool to use, because in the first place you put things together and then you create a link on how the terms are related, so in that way it is much easier for one to understand processes rather than looking for them like how the step is presented in the book.' (FGD2 P1) 'After starting to use concept map, I become curious to study physiology because you just want to study more chapters.' (FGD3 P6)

Participants indicated that concept mapping assisted them to focus on the most important course content, which acted as the foundation for understanding other content. Consequently, students developed a broader view of the content and an ability to identify what is important for understanding other physiological processes:

'I find it easy to identify what is important, what I mean is ... you know there are some topics that we have to understand before moving to the next topic. Some topics are more like introductory to complicated ones.' (FGD1 P5)

Participants furthermore indicated that concept mapping improved their assimilation of knowledge, which means that they are able to link new information to their pre-existing knowledge, therefore making it easy to understand new information in the course. Moreover, students indicated that concept mapping made revision of their work stress free, as they could easily locate information in the textbooks and notes:

'My perception is that concept mapping helps me understand new information through linking to what I learnt in the past. For example, what I did with endocrine system, I first start mapping anatomical concepts I learn in first year then I embedded new physiology concepts.' (FGD3 P4)

'With concept maps, I know exactly where to get information when I am looking for something to learn.' (FGD2 P4)

\section{Theme 2: Concept mapping as a group activity}

This study revealed that concept mapping promotes group work. The participants reported that by using concept mapping, communication in the group improved, making individual contributions to the group helpful to others. With concept mapping, students had an opportunity to identify areas that need future collaboration in terms of forming smaller study groups to discuss further course content. Some participants felt that concept mapping could assist them to identify topics that needed scaffolding from their peers or teachers:

'Actually we did concept mapping in groups, it was easy to communicate. We bring together our different understanding and it was possible to help each other.' (FGD1 P3)

'First we discuss concepts in a group, if there's something we do not understand as a group we ask for assistance from a colleague or our lecturer.' (FGD2 P4)

\section{Theme 3: Perceived effects of concept mapping on students' academic performance}

Students indicated that human physiology is a complex course and consists of a large volume of content; therefore, they tend to learn using a surface approach. When students memorised, they were not able to link and apply information. However, by using concept maps, participants were optimistic that their performance would improve because they thought their understanding had improved. Improvement of academic performance was not only hoped for in human physiology, but also in other courses, as concept mapping is also suitable for application to other courses:

'I use to memorise a lot but when I am taking a test, I can't even remember what I learn, with concept maps, I just have to jot down main concepts and then to explain a certain process, this really help me pass.' (FGD3 P4)

Other participants added:

'It [concept mapping] is really helping because we are now able to relate physiology to other modules and even clinical practice, that way it improves my overall performance, I'm positive and have high hope to excel in the coming exams.' (FGD3 P2)

'It's good that we are introduced to this method, we can also make use of it in other subjects which are problematic, it really help us to do better, oh this nursing school is just too much.' (FGD1 P3)

\section{Theme 4: Perceived implications of concept mapping on learning resources}

For learning to take place, students should interact with different resources, such as hard copies of textbooks, e-books, journal articles and online resources as blogs. In the current study, participants reported that concept mapping required them to gather more information from different resources to construct their maps:

'For one to come up with a concept map, you need to consult as many titles as possible, especially me I like to write in my own understanding so using one book is not enough.' (FGD3 P3)

Time is another resource that is required by individuals to perform any activity, i.e. students also need time for learning activities. In this study, constructing concept maps was perceived to be time consuming; this is because a student first needs to read up on a topic, think about it and reflect on it. Making links and defining concepts also need time and, especially if the learning resource is not clear, a student may be obliged to consult other resources, which also requires a lot of time:

'Concept mapping is not that easy, it really needs one to have time but we are very busy. All I can say is that it's really time consuming because we try to understand and put information in our own perspectives.' (FGP2 P5) 'It [concept mapping] requires more time, like you have to come up with everything and you branch it and sometimes it is so hard to come up with one idea when you are working in a group like people think differently' (FGP3 P6)

Owing to the limited number of textbooks in the public and university libraries, students seek information from online sources such as Google Scholar, YouTube videos and other accessible learning websites. Students found this to be a burden because of poor internet connections and the high cost of connectivity. Students perceived that they needed access to the internet to search for online information to deepen their understanding before constructing concept maps:

'I would say it is more challenging when it comes to access to internet, we need to look for information from online resources and it is costly. (FGD3 P5) 
'You have to search, you have to get more material and so on, and sometimes the content is too much and needs more time to review .... . We went to the library searching from different books but we didn't really get enough but we also googled.' (FGD1 P3)

\section{Discussion}

This study revealed that nursing students perceive concept mapping as a facilitator of deep learning. In deep learning, students are actively involved, curious, determined and seek for meanings. ${ }^{[17]}$ It is important for students to engage in deep learning in human physiology, as class contact is short compared with the content that has to be covered.

Deep learning in foundational subjects such as human physiology may improve students' ability to think critically and reason clinically. According to Cárnio, ${ }^{[18]}$ nursing is a profession that uses a comprehensive knowledge area and, therefore, cannot be practised without a knowledge of the basic sciences, as students may not reason without such basic knowledge. Additionally, the successful application of human physiology to clinical practice and other courses helps students to relate knowledge to diseases and different health conditions. ${ }^{[18]}$ Students are required to have a deeper understanding of human physiology and be knowledgeable regarding the physiological processes. Therefore, basic science courses, including human physiology, are designed to enhance nursing students' academic success and are important for safe practice throughout their career as nurses. ${ }^{[19]}$ The finding that concept mapping promotes deep learning correlates with that of Khrais and Saleh, ${ }^{[11]}$ who reported that concept mapping transforms passive students into active ones. The findings of the current study demonstrate that the students are aware of prerequisite and important information that they have to understand before proceeding to more advanced content. Similarly, Daley et al. ${ }^{[20]}$ reported that with application of concept mapping as a learning tool, students were able to focus on clinically important materials.

In the undergraduate nursing degree programme, students are engaged in group activities for the purpose of assessment or as a learning activity. For learning purposes, they identify a peer to work with and meet on a regular basis to discuss academic work, which also includes using concept mapping. This study reveals that concept mapping is also undertaken as a group activity. As a result, it can promote collaborative learning through constructive interaction between students and it also helps them to identify areas that need more elaboration by their lecturers. Concept mapping is an interactive activity and creations made by students may differ, ${ }^{[2]}$ thus encouraging students to share information with one another. This promotes students' active participation and learning in the process. The findings of the current study are in accordance with those of Campbell, ${ }^{[22]}$ who indicated that students tend to compare their maps and take note of how their connections are similar to or differ from those of their peers. Furthermore, concept maps may afford students an opportunity to share their thinking and understanding on a particular topic. ${ }^{[22]}$ The current study reveals that concept mapping may help to build teams. Abd El-Hay et al. ${ }^{[10]}$ reported that $55 \%$ of their participants agreed that they become friendly with their group members when they use concept maps.

Despite the integrative nature of the content and difficult concepts in human physiology, students perceived that concept mapping would contribute positively to their academic performance. When using concept mapping, there is no need to study human physiology using memorisation. ${ }^{[23]}$ In addition, it is possible to display causal relationships, ${ }^{[23]}$ which are commonly used to show how physiological processes occur and how body systems are integrated. Although concept mapping was introduced to this group of students for learning physiology, participants indicated that it may improve overall performance in other courses and assist in the application of theory in practice. Similarly, Harrison and Gibbons ${ }^{[24]}$ indicated that nursing students perceive concept mapping as a helpful tool to organise theoretical knowledge and promote ease of correlation with practical components. The undergraduate nursing degree curriculum stipulates the human physiology course as a prerequisite for general nursing, midwifery and pharmacology at third-year level. Students are also expected to integrate human physiology with daily clinical practice. As shown in this study, the use of concept mapping makes it easy to apply human physiology to other courses, including clinical practice, irrespective of the students' settings.

This study was conducted at a campus located in a resourceconstrained setting. Therefore, the problems of limited internet access and lack of learning resources, such as textbooks, as indicated by the study participants, are not limited to this nursing programme or this campus, but may apply to all resource-constrained settings. Other than learning materials, participants perceived that concept mapping is time consuming. Creating concept maps entails creativity, reflection and insight, ${ }^{[24]}$ which indicates that it takes time to construct concept maps, and at the same time one needs to prepare thoroughly by consulting different materials. It is recommended that students be guided on time-management strategies, as well as the learning resource options available in a resource-constrained setting. There is a need for libraries to put forward an effective strategy to ensure that the minimal resources available are accessible to all students for learning purposes. As human physiology is considered a difficult course that is associated with poor performance, it is recommended that concept mapping be fully integrated into learning activities, given its perceived positive effect on learning. As a way forward, the researchers propose that students should construct concept maps at the end of each session and revise them regularly as new understandings and perspectives on the subject content develop.

\section{Conclusions}

Future research should consider exploring the use of concept mapping as a teaching and assessment tool in nursing degree programmes and other health science programmes. There is also a need to study the relationship between concept mapping and students' academic performance, as well as exploring how concept mapping can be used for learning to manage different conditions in clinical settings. Data collection for this study was done a few weeks before the second-semester examinations. This is considered to be a limitation because it was challenging to agree upon the focus group discussion schedule with the students.

Deep knowledge of human physiology is important, as it provides the foundational knowledge needed by students to apply critical thinking and clinical reasoning. Nursing students experienced and perceived concept mapping as a tool that supports deep learning and teamwork and improves academic performance. However, more time is required to construct concept maps, as they require various learning resources that have to be consulted. The researchers recommend that nursing students should be supported to extend the use of concept maps to other courses, as this may improve their learning experiences despite the lack of learning resources. 
Declaration. The research for this study was done in partial fulfilment of the requirement for SKF's Bachelor of Nursing Science (Clinical) Honours degree at the University of Namibia.

Acknowledgements. The authors would like to acknowledge the campus library staff, who assisted during the literature search process.

Author contributions. All authors were involved in the conceptualisation, data collection and analysis, literature review and writing of the manuscript.

Funding. None.

\section{Conflicts of interest. None.}

1. Yang HH. Beliefs and concept mapping on WebQuest development. In: Handbook of Research on Instructiona Systems and Technology. London: IGI Global, 2008:272-286.

. Gerdeman JL, Lux K, Jacko J. Using concept mapping to build clinical judgment skills. Nurse Educ Pract 2013;13(1):11-17. https://doi.org/10.1016/.nepr.2012.05.009

3. Daley BJ, Durning SJ, Torre DM. Using concept maps to create meaningful learning in medical education MedEdPublish 2016;5(1):1-29. https://doi.org/10.15694/mep.2016.000019

4. Kaddoura M, VanDyke O, Cheng B, Shea-Foisy K. Impact of concept mapping on the development of clinical judgment skills in nursing students. Teach Learn Nurs 2016;11(3):101-107. https://doi.org/10.1016/j. teln.2016.02.001

5. Rahnama F, Mardani-Hamooleh M. Iranian nursing students' perceptions regarding use of concept mapping: A content analysis. Res Dev Med Educ 2017;6(1):45-50. https://doi.org/10.15171/rdme.2017.008

6. Wei W, Yue K-B. Integrating concept mapping into information systems education for meaningful learning and assessment. Inf Syst Educ J 2017;15(6):4-16.

7. Vodovozov V, Raud Z. Concept maps for teaching, learning, and assessment in electronics. Educ Res In 2015;2015:1-9. https://doi.org/10.1155/2015/84967

8. Conceição SCO, Samuel A, Yelich Biniecki SM. Using concept mapping as a tool for conducting research: An analysis of three approaches. Cogent Soc Sci 2017;3(1). https://doi.org/10.1080/23311886.2017.1404753

9. Chabeli M. Concept-mapping as a teaching method to facilitate critical thinking in nursing education: A review of the literature. Heal SA Gesondheid 2010;15(1):1-7. https://doi.org/10.4102/hsag.v15i1.432
10. Abd El-Hay SA, El Mezayen SE, Ahmed RE. Effect of concept mapping on problem solving skills, competence in clinical setting and knowledge among undergraduate nursing students. J Nurs Educ Pract 2018;8(8):34. https:/ doi.org/10.5430/jnep.v8n8p34

1. Khrais $\mathrm{H}$, Saleh A. The outcomes of integrating concept mapping in nursing education: An integrative review. Open J Nurs 2017;7(11):1335-1347. https://doi.org/10.4236/oin.2017.711096

12. Creswell J. Qualitative Inquiry and Research Design: Choosing among Five Approaches. 3rd ed. Los Angeles: SAGE, 2013:1-448

13. Botma Y, Greeff M, Mulaudzi FM, Wright S. Research in Health Sciences. Cape Town: Heinemann, 2010.

14. Creswell J. Research Design: Qualitative, Quantitative and Mixed Methods Approaches. 4th ed. London: SAGE, 2014:1-273.

15. Whittemore R, Chase S, Mandle L. Validity in qualitative research. Qual Res 2001;2(4):522-537. https://doi.org/ 10.1177\%2F10497320112911929

16. Polit D, Beck C. Nursing Research: Generating and Assessing Evidence for Nursing Practice. 10th ed Philadelphia: Wolters Kluwer, 2017:1-784

17. Bran C. Strategies for developing a deep approach of learning in higher education. J Plus Educ 2014;11(2):130-140.

18. Cárnio EC. Basic sciences and nursing. Rev Lat Am Enfermagem 2011;19(5):1061-1062. https://doi.org/10.1590/ S0104-11692011000500001

19. Cetindag A, Taskin Yilmaz F, Vicil S, Basli M, Ahmet Arslan S. Views of nursing students on basic medical sciences courses. Educ Res Med Sci 2018;7(1):1-6. https://doi.org/10.5812/erms.80220

20. Daley BJ, Morgan S, Black SB. Concept maps in nursing education: A historical literature review and research directions. J Nurs Educ 2016;55(11):631-639. https://doi.org/10.3928/01484834-20161011-05

21. Guy R, Byrne B, Dobos M. Stop think: A simple approach to encourage the self-assessment of learning. Adv Physiol Educ 2017:41(1):130-136. https://doi.org/10.1152/advan.00174.2016

22. Campbell LO. Concept mapping: An 'instagram' of students' thinking. Soc Stud 2016;107(2):74-80. https://doi. org/10.1080/00377996.2015.1124377

23. Henige K. Use of concept mapping in an undergraduate introductory exercise physiology course. Adv Physiol Educ 2012;36(3):197-206. https://doi.org/10.1152/advan.00001.2012

24. Harrison S, Gibbons C. Nursing student perceptions of concept maps: From theory to practice. Nurs Educ Perspect 2013;34(6):395-399. https://doi.org/10.5480/10-46

Accepted 16 June 2020. 